\title{
Seismic performance of RC frame structures with magnesium-steel seismic reduction braces
}

\author{
Yinfeng Dong ${ }^{\mathrm{a}}$, Song Lin, Peng $\mathrm{Xu}$ and Ying $\mathrm{Hu}$ \\ Key Laboratory of New Technology for Construction of Cities in Mountain Area \\ (Chongqing University), Ministry of Education, Chongqing, 400045, China, \\ School of Civil Engineering, Chongqing University, Chongqing, 400045, China
}

\begin{abstract}
To improve the self-centering and seismic reduction performance of seismic reduction braces, Magnesium alloy is used to replace the steel as core material of seismic reduction braces for the first time. Braces respectively with two different core material of steel and magnesium alloy are placed in a RC frame structure, its seismic response under frequent and rare earthquakes are analyzed and compared. Results show that both of the seismic reduction braces with two types of core material have an obvious impact on story shear force, displacement and residual deformation in the RC frame structure. Magnesium alloy seismic reduction braces have better performance than steel seismic reduction braces in reducing story drift and residual deformation in RC frame. Moreover, for magnesium alloy seismic reduction brace, its merit of self-centering ability is worthy of consideration for future research.
\end{abstract}

Keywords: seismic action, magnesium alloy, seismic reduction braces, $\mathrm{RC}$ frame.

\section{Introduction}

Seismic reduction brace is a kind of common seismic reduction braces. Both tension and compression it can reach the full section yield after entering into plastic stage. It do not cause significant changes in structural stiffness[1]. In China, the application of seismic reduction brace has been gradually spread since 2000[2].

At present, many experimental and theoretical studies have been carried out on the seismic reduction braces. The full hysteresis curve was obtained, after a series of tensile and compressive tests on a group of precast concrete boards added plates were carried out by Wakabayashi[3]. However, the system is easily destroyed by the failure of precast concrete boards because the constraint effect of prefabricated plate on steel plate is easily influenced by the reinforcement ratio of prefabricated plate. Starting from the test results of Wakabayashi, Fujimoto overcomes its disadvantages and successfully developed a series of seismic reduction brace that have stronger restrained ability and more stable core material, then he gives the stiffness and strength design criterion of steelcasing[4].

Nishimoto conducted a number of experiments on braces that has the cross section of steel core. The experimental results show that such braces has a very full and smooth hysteresis curve, which has been subjected to repeated load, its excellent anti fatigue ability is verified[5]. Chen as one of the pioneer scholars to research the seismic reduction brace tries to restrain the core material that has low yield point by filling the concrete in steel casing and does experimental research on restoring force

${ }^{a}$ Corresponding author : dongyinfeng@cqu.edu.cn 
performance of such braces[6]. Cai developed a seismic reduction brace with core material of double steel plate. Furthermore, he carried out the cyclic loading as well as fatigue test. The results show that such seismic reduction brace not only has a stable deformation performance but also has a full hysteresis curve. So such brace can absorb $90 \%$ of the energy under earthquakes[7].

At present, although the study of seismic reduction brace is more and more extensive but seismic reduction braces with new core material, its analysis and design theory is imperfect. With light weight, high strength and high deformation ability, Magnesium alloy is a kind of high performance materials[8] Recently, magnesium alloy as an emerging material has been widely used in military, aviation, automobile and other fields[9]. However, magnesium alloy used in civil engineering as building materials has no precedent. The paper shows the seismic response of seismic reduction braces respectively with two different core material of steel and magnesium alloy placed in a RC frame structure in order to provide ideas for the magnesium alloy seismic reduction brace used in the $\mathrm{RC}$ frames.

\section{Basic case of structure and analysis}

\subsection{Site condition and structure arrangement}

The paper take a RC frame structure as an example, its seismic fortification intensity is 7 degrees, design basic acceleration peak value is $0.15 \mathrm{~g}$ and classification of design earthquakes is the second group.The structure has five floors in total, the first floor isfor the service hall, its story is $4.7 \mathrm{~m}$ which is relatively high and the rest of the four floors are for administrative offices, each story is $4.2 \mathrm{~m}$. There are three vertical cross in total,the span of each cross is $7.2 \mathrm{~m}$ and the total span is $21.6 \mathrm{~m}$. Besidesthere are three horizontal cross in total, each span respectively is $7.2 \mathrm{~m}, 2.8 \mathrm{~m}$ and $7.2 \mathrm{~m}$ and the total span is $17.2 \mathrm{~m}$. The main beam column section size of the model is as follows:bottom columns $500 \mathrm{~mm} \times$ $500 \mathrm{~mm}$,two layers and above $450 \mathrm{~mm} \times 450 \mathrm{~mm}$; all the main beams are $250 \times 600 \mathrm{mmand}$ all the secondary girders are $250 \mathrm{~mm} \times 500 \mathrm{~mm}$. The RC frame structure elevation is shown in Figure 1 .

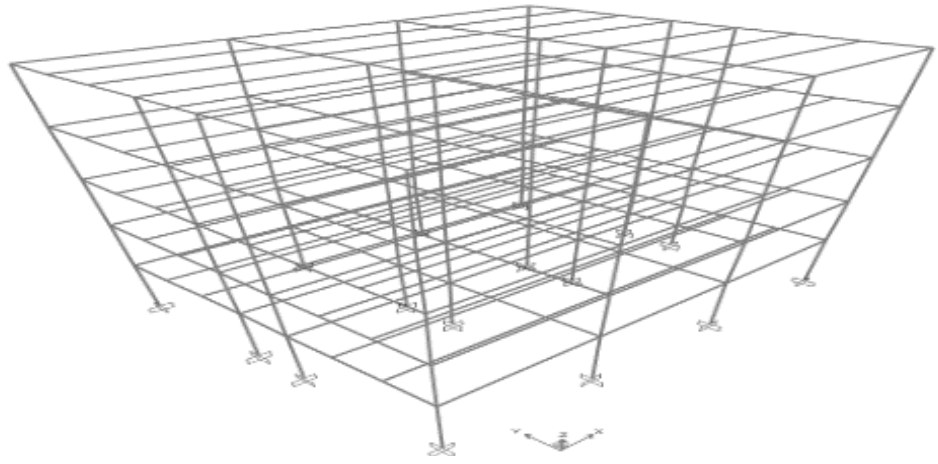

Figure 1. 3D view of the Office Building.

\subsection{Selection of ground motions}

In this paper, an artificial ground motion and two real ground motions are selected for analysis based on the code for seismic design of buildings in China (50011-2010 GB). The acceleration time history curves of the three seismic waves are given in Figure 2. 


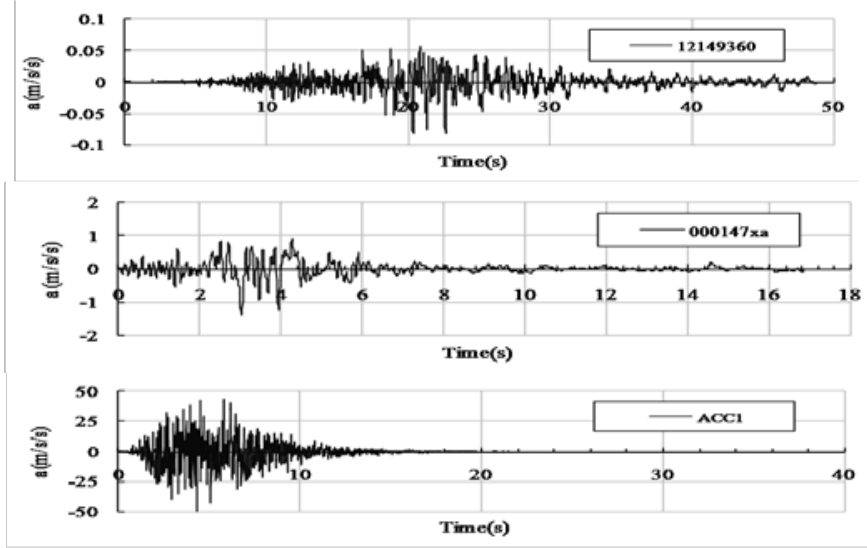

Figure 2. Seismic acceleration time history curve.

\subsection{Configuration of the brace}

Before making comparative analysis of seismic reduction braces respectively with two different core material of steel and magnesium alloy. The principle of the two braces placed in a RC frame structure is that the stiffness of such two braces are equal. The geometrical and physical properties of the two different core material of steel and magnesium alloy used in the paper are as follows: section size of core material of steel is $500 \mathrm{~mm}^{2}$, its elastic modulus is $210 \mathrm{GPa}$ and ultimate strength is $80 \mathrm{kN}$. The section size of core material of magnesium alloy is $2000 \mathrm{~mm}^{2}$, its elastic modulus is $45 \mathrm{GPa}$ and ultimate strength is $500 \mathrm{kN}$. The layout scheme of the brace is shown in Figure 3.
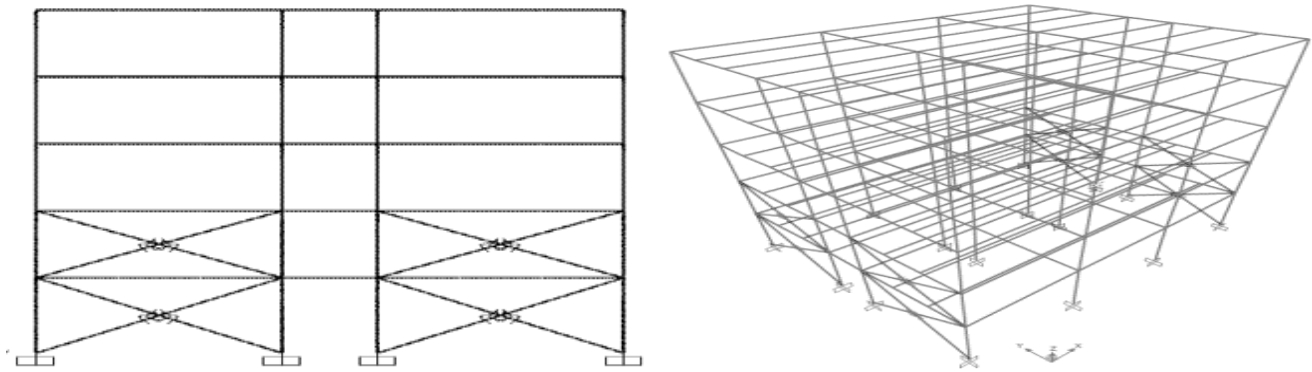

Figure 3. The location of braces $\mathrm{s}$ in the first and second floor.

\section{Seismic performance evaluation}

\subsection{Story shear}

The story shear force placed the seismic reduction braces with two different core material, its distribution are basically the same under frequent earthquakes. The bottom shear force in original RC frame structure is $909.7 \mathrm{kN}$. While the bottom shear force in the structure placed core material magnesium alloy braces is $941.6 \mathrm{kN}$, which is $3 \%$ times compared with the original one. Under the action of rare earthquakes, the distribution of the story shear force is uniform among each floor and the change rule is basically the same.

The bottom shear force are $4955.2 \mathrm{kN}, 3817.6 \mathrm{kN}$ and $3026.5 \mathrm{kN}$ in the order of the RC frame structure respectively placed seismic reduction braces with core material of steel and magnesium alloy, the last one is for the original RC frame structure. From the data, it can be seen that the bottom shear force placed seismic reduction braces with core material of steel is 1.64 times than that of the original one, which is 1.3 times than that of the magnesium alloy one. It shows that the increase of story shear 
force due to the placement of seismic reduction braces. The increase of story shear force inRC frame structure placed seismic reduction braces with core material of magnesium alloy is much smaller than that placed steel.

By taking the maximum shear of each seismic wave, the envelope diagram of the structure under frequent earthquakes and rare earthquakes is as shown in Figure 4.

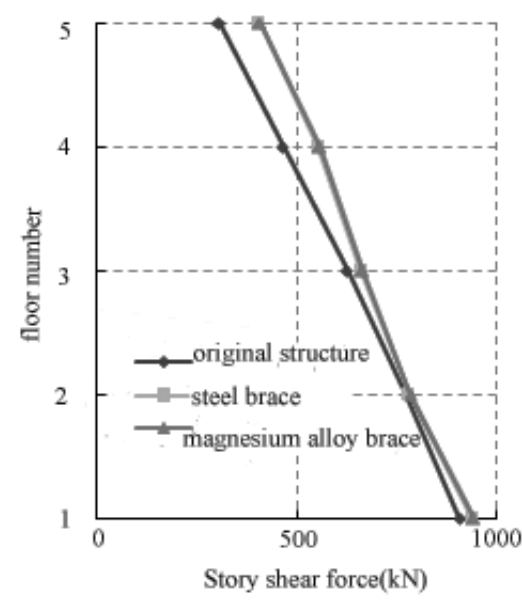

(a)Frequent earthquakes

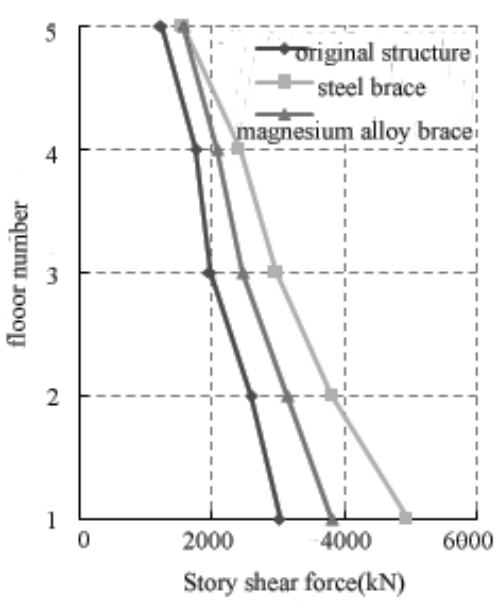

(b) Rare earthquakes

Figure 4. Story shear force under frequent and rare earthquakes.

\subsection{Story drift angle}

China's code for seismic design of buildings (50011-2010 GB)clearly stipulates that the limit of the story drift angle for RC frame structures in elastic state is $1 / 550$.while for the RC frame structure in the plastic state, the limit of the story drift angle is $1 / 50 \mathrm{rad}$.

In the same way, the envelope diagram of the structure under frequent earthquakes and rare earthquakes is as shown in Figure 5 by taking the maximum story drift angle of each seismic wave. From the figure, it can be seen that the story drift angle of the original RC frame structure can meet the requirements of the code no matter what there are frequent or rare earthquakes, the change rule of story drift angle is basically the same. Under frequent earthquakes, the story drift angle of the RC frame structures placed two different core material of seismic reduction braces is basically the same, because the stiffness of the two different braces are equal.

Under the rare earthquakes, the displacement of the structure placed braces was obviously reduced. The displacement of the original structure in the second story can reach to $43.3 \mathrm{~mm}$. The RC frame structure, after placed the steel braces, its displacement can be reduced to $30 \mathrm{~mm}$, whileafter placed the steel braces, its displacement can be reduced to $24.5 \mathrm{~mm}$. In general, the displacement of RC frame structure placed the magnesium alloy braces is better than that of placed the steel one under rare earthquakes. 


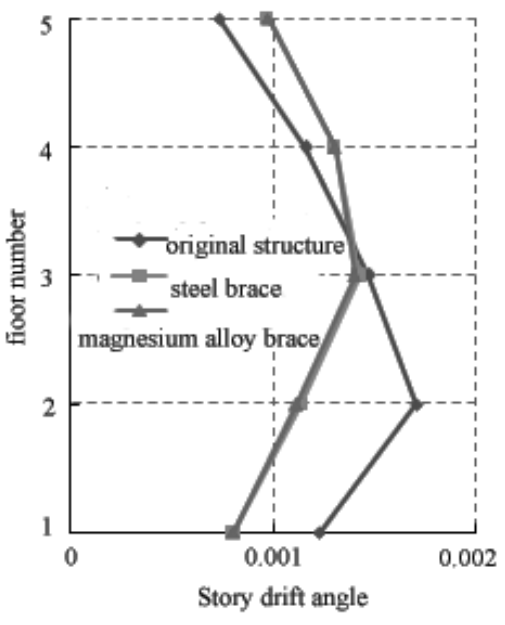

(a) Frequent earthquakes

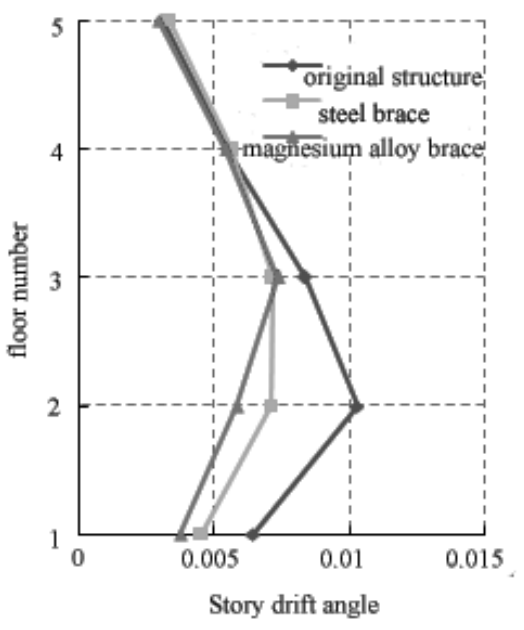

(b) Rare earthquakes

Figure 5. Maximum story drift angle under frequent and rare earthquakes.

\subsection{Displacement time history}

Under the 000147xa ground motion, the paper takes the displacement time history of the upper node of a corner column as an example in order to compare the displacement change before and after placing the braces in RC frame structure. The position of the column is shown in Figure 6.

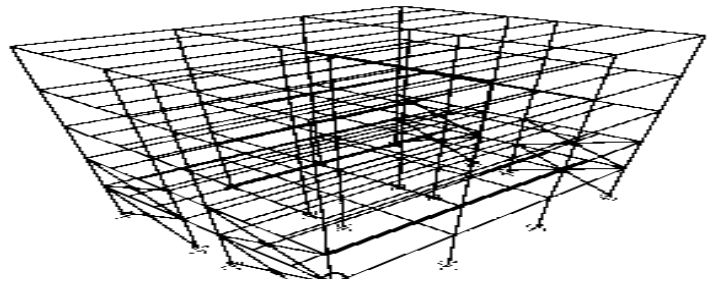

Figure 6. The location of Column for time history analysis.

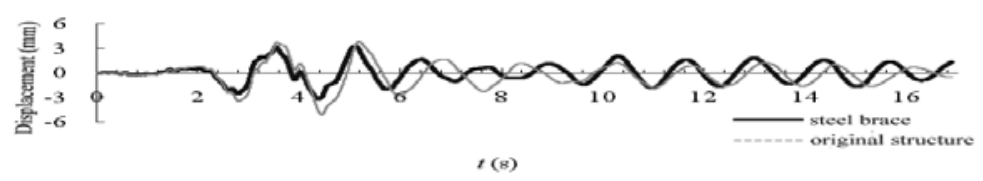

(a) Original structure and steel brace structure

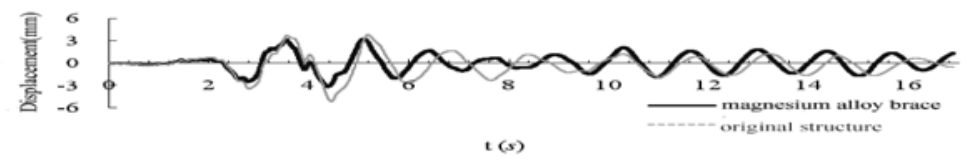

(b) Original structure and magnesium alloy brace structure

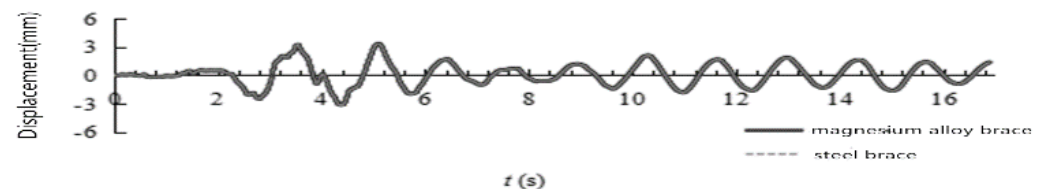

(c) Steel brace structure and magnesium alloy brace structure

Figure 7. Displacement of the upper joint of a corner column under frequent earthquakes. 


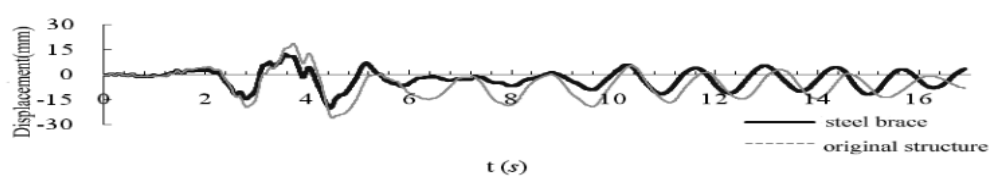

(a) Original structure and steel brace structure

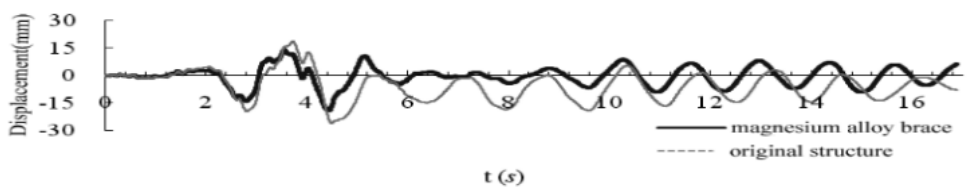

(b) Original structure and magnesium alloy brace structure

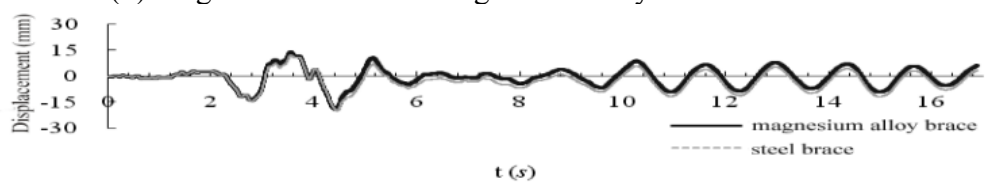

(c) Steel brace structure and magnesium alloy brace structure

Figure 8. Displacement of the upper joint of a corner column under rare earthquakes.

It can be seen from the Figures 7 and 8 that the steel seismic reduction brace and the magnesium alloys seismic reduction braces have the same weakening effect on structure displacement no matter there are frequent or rare earthquakes. The magnesium alloy seismic reduction brace is better than that of steel one in the limit of the maximum displacement of the RC frame structure. After $12 \mathrm{~s}$, the seismic effect is weakened, then the paper takes the maximum and minimum mean values of all the displacement, finally the average of such two mean is the final residual deformation. Under rare earthquakes, the residual deformation of the original structure is $6.2 \mathrm{~mm}$, while the structure placed steel braces is $3.2 \mathrm{~mm}$ and the structure placed magnesium alloy braces is $0.5 \mathrm{~mm}$. It is obvious that the $\mathrm{RC}$ frame structure placed magnesium alloy braces, its residual deformation is much less than that of the other two cases. Therefore, the seismic reduction brace of magnesium alloy has excellent performance in self-centering and seismic reduction.

\section{Conclusion}

Seismic reduction braces respectively with two different core material of steel and magnesium alloy are placed in a RC frame structure. The seismic response of the structure under frequent and rare earthquakes are analyzed and compared in the paper. The main conclusions are as follows:

1. Both of the seismic reduction braces with two types of material have an obvious increase on story shear force, but the magnesium alloy braces structure of the shear value increase is much smaller than that of the steel braces structure.

2. Both of the seismic reduction braces with two types of material have an obvious impact on story displacement and residual deformation in the RC frame structure. Magnesium alloy seismic reduction braces have better performance than steel seismic reduction braces in reducing story drift and residual deformation in $\mathrm{RC}$ frame structure.

3.Under the action of rare earthquakes, for magnesium alloy seismic reduction brace, its selfcentering ability is perfect due to high strength and good elasticity.

4.The paper only shows the seismic performance of two types of seismic reduction braces in $\mathrm{RC}$ frame structure, while the seismic performance of the magnesium alloy seismic reduction brace placed in the steel structure or other structures needs further research.

\section{Acknowledgments}

This work is supported by National Natural Science Foundation of China under Grant No. 1080210. 


\section{References}

1. G.P.Qiang.Structural Engineers, 2012, 28(3): 102-108.in Chinese

2. Y.L.Guo,B.H.Zhang, X.A.Wang, et al. Journal of Architecture and Civil Engineering, 2013, 30(1): 1-12.in Chinese

3. Wakabayashi M, Nakamura T, KashibaraA, et al. Experimental study of elasto-plastic properties of precast concrete wall panels with built-in insulating braces. Summaries of Technical Papers of Annual Meeting, Architectural Institute of Japan, 1973.

4. Watanabe A, Hitomi Y, Saeki E, et al. Properties of Brace Encased in Buckling-Restraining Concrete and Steel Tube. Proceedings of the Ninth World conference on earthquakes Engineering, August, Tokyo-Kyoto, Japana,1988.

5. Nishimoto K, Shirai T, Nakata $Y$, et al. Sub-assembly Testing of large buckling-restraint unbonded braces. The Third International Conference on earthquakes Engineering, Nanjing. PR. China, 2004.

6. Z.C.Chen. Progress in Steal Building Structures, 2005, 7(5): 29-35.in Chinese

7. K.Q.Cai, Y.Z.Huang, C.X.Weng. Progress in Steal Building Structures, 2005, 7(3):1-8.in Chinese

8. ASM International, Magnesium and Magnesium Alloy.OH: Metal Park, 1999.

9. Kojima Y. Mater. Sci. Forum, 2000, 350 351: 3-12. 